estudios 


\title{
Fuera esas manos tintas en sangre. La poesía antiimperialista de Raúl González Tuñón
}

\author{
Get out these bloods stained hands.
}

The anti-imperialist poetry of Raúl González Tuñón

Fora daqui essas mãos tingidas de sangue.

A poesía anti-imperialista de Raúl González Tuñón

\section{María Fernanda Alle}

INSTITUTO DE ESTUdios CRÍtICOS EN HUMANIDADES (IECH),

UNIVERSIDAD NACIONAL DE ROSARIO; CONSEJO NACIONAL DE INVESTIGACIONES CIENTÍFICAS Y TÉCNICAS (CONICET), ARGENTINA

Doctora en Humanidades y Artes, mención Literatura. Ha publicado artículos en diversas revistas académicas de la especialidad, entre ellos: "La eficacia política de la poesía según Raúl González Tunoón: hacia la definición de una poética de la convocatoria" (El jardín de los poetas, 2015); "Primer canto argentino de Raúl González Tuñón en 1943 y en 1945: la eficacia política de la poesía" (Orbis Tertius, 2014); "La literatura Resplandeciente de Raúl González Tuñón: entre la moral partidaria y la afirmación de la aventura" (Cuadernos del Cilha, 2012) y "La imagen de escritor de Raúl González Tuñón, de los años sesenta a los treinta: relaciones entre literatura y política" (A Contracorriente, 2012). Coordinó y colaboró en el dossier "Literatura, cultura y pensamiento de izquierdas en la Argentina del siglo XX" (Badebec, 2015). Correo electrónico: yfernandaa@gmail.com

\section{Artículo de investigación}

El artículo presentado forma parte de los resultados finales de la tesis doctoral de la autora, defendida en diciembre del año 2015 y calificada con 10 (sobresaliente) con recomendación de publicación. La investigación fue financiada por CONICET (periodo: abril de 2010-marzo de 2015).

Documento accesible en línea desde la siguiente dirección: http://revistas.javeriana.edu.co doi:10.11144/Javeriana.cl22-44.fmts 


\section{Resumen}

Este artículo revisa críticamente la producción de Raúl González Tuñón de las décadas del cincuenta y sesenta, a la luz de los programas de acción que, en el contexto de la Guerra Fría, formula el Partido Comunista. En esta dirección, se analizan, en primer lugar, los textos programáticos del autor, en los cuales explicita un proyecto literario para los países latinoamericanos, sometidos a la amenaza imperialista. A partir de los lineamientos de ese proyecto se leen, luego, los poemas del autor como una intervención ligada a las consignas partidarias de la defensa de la libertad cultural y la lucha por la paz.

Palabras clave: Raúl González Tuñón; Congreso Continental de la Cultura; Guerra Fría; antiimperialismo; poética de la convocatoria

\section{Abstract}

This article reviews Raul Gonzalez Tuñón's production between 1950 and 1960 in the light of the Communist Party's action programs in the context of the Cold War. Firstly, the programmatic texts where he explicitly posits a literary project for the Latin American countries under imperialist threat are analyzed. Then, the guidelines of this project are taken as a starting point for reading his poems, as an intervention linked to the party's slogans for cultural freedom and the struggle for peace.

Keywords: Raúl González Tuñon; Continental Congress of Culture; Cold War; Antiimperialism; Poetics of the summons

\section{Resumo}

Este artigo revisa criticamente a produção de Raúl González Tuñón da década de 50 e 60, à luz dos programas de ação que, no contexto da Guerra Fria, o Partido Comunista formula. Nesta direção são analisados, em primeiro lugar, os textos programáticos do autor, em que explicita um projeto literário para os países latino-americanos submetidos à ameaça imperialista. A partir das diretrizes desse projeto os poemas do autor são lidos como uma intervenção ligada aos slogans partidários da defensa da liberdade cultural e a luta pela paz.

Palavras-chave: Raúl González Tuñón; Congresso Continental da Cultura; Guerra Fria; anti-imperialismo; poética do chamado 
"A las puertas de la Historia golpea innumerable grito: ¡Fuera esas manos tintas en sangre, de Corea!” RGT, CORAL COREA (1)

\section{Guerra Fría, antiimperialismo y defensa de la paz}

Como señala Eric Hobsbawm, si bien los 45 años transcurridos entre la explosión de las bombas atómicas en Hiroshima y Nagasaki y el inicio de la Perestroika, no constituyen un periodo "homogéneo", lo cierto es que, en su conjunto, ese bloque temporal siguió "un patrón único marcado por la peculiar situación internacional que lo dominó" (230), cuya clave fue "el enfrentamiento constante de las dos superpotencias surgidas de la segunda guerra mundial": la Unión Soviética y los Estados Unidos. ${ }^{1}$

En el marco de esa división mundial en dos grandes potencias antagónicas, será el imperialismo norteamericano el principal enemigo internacional ante el cual el Partido Comunista defina sus programas de acción. Tal como explica Adriana Petra, en septiembre de 1947, en una reunión secreta que se llevó a cabo en Polonia, "los soviéticos oficializaron al mundo, por la voz de su delegado Andrei Zhdánov, la ruptura de la gran alianza nacida de la guerra" y, con ella, la división del mundo en dos grandes bloques: "de un lado, el campo imperialista y antidemocrático, dominado por los Estados Unidos; del otro, el campo antiimperialista, democrático y defensor de la paz, hegemonizado por la URSS" (184). De acuerdo a ese diagnóstico, sostiene Petra, "la tarea principal" a la que se abocarán los partidos comunistas de todo el mundo será "la 'lucha por la paz' $[\ldots]$, la resistencia a los planes de expansión y dominación imperialista en todos los terrenos y, particularmente, en los grandes países

1 De acuerdo con Hobsbawm, la singularidad de los años de la Guerra Fría gravitó en torno al hecho de que, más allá de la "retórica apocalíptica" dominante en el discurso oficial de ambos bandos, no existió en realidad "ningún peligro inminente de guerra mundial" (230). De este modo, para Hobsbawm, hasta mediados de la década del 70, cuando el sistema internacional entra en un nuevo y prolongado periodo de crisis política y económica, "ambas superpotencias [...] habían hecho los máximos esfuerzos por resolver las disputas sobre sus zonas de influencia sin llegar a un choque abierto de sus fuerzas armadas que pudiese llevarlas a la guerra y, en contra de la ideología y de la retórica de la guerra fría, habían actuado partiendo de la premisa de que la coexistencia pacífica entre ambas era posible" (232). 
occidentales, la defensa de la independencia nacional y la soberanía de cada país" (185). A su vez, esa "defensa de la soberanía nacional frente a los embates del imperialismo norteamericano" que se impuso como tarea el PC "se tradujo en términos culturales en la organización de un discurso que, mediante la condena al 'cosmopolitismo', pretendió defender y revalorizar las 'culturas nacionales' [...]" (215).

En efecto, según se desprende del análisis de la situación presentado por Oscar Arévalo en su historia "oficial" del PCA, ${ }^{2}$ una vez "derrotado el fascismo" la situación internacional virará hacia una redefinición de los antagonismos en tanto, a partir de ese momento, "se desenvuelve una lucha aguda, muy tenaz, entre el socialismo -que se desarrolla como sistema mundial-y el imperialismo [...] que se esfuerza por todos los medios, económicos, políticos y militares, por impedir el avance del progreso social de la humanidad" (70). Esos "esfuerzos" realizados por el imperialismo, que van desde guerras declaradas hasta políticas de explotación económica, social y racial, son explicados por Arévalo de acuerdo a un diagnóstico optimista del escenario abierto por la posguerra, según el cual "el socialismo se abre camino en nuevos países, avanza el desmoronamiento del sistema colonial por el auge de las luchas de liberación nacional de los pueblos, crece cada vez más potente la lucha de la clase obrera en los países capitalistas" (70). Ante este nuevo panorama, el camino de acción definido por el partido en Latinoamérica consistió, siguiendo al autor, en "la lucha por la democracia política, frente a los regímenes dictatoriales y contra la inestabilidad" (70) y, en lo que respecta a la política exterior, "la lucha por la paz" (79): un programa que, como veremos, es el sustrato a partir del cual se construye la literatura de Raúl González Tuñón a lo largo de las décadas del cincuenta y del sesenta.

Desde inicios de los años treinta, González Tuñón comienza a formular en sus textos programáticos, y a ensayar en su literatura, un proyecto de intervención poético-político que tiene hondas vinculaciones, explícitamente enunciadas, con los programas de acción culturales y políticos del PC; partido al que se afilia en 1934 y del que nunca se desvinculará. En este sentido, la búsqueda poética que caracteriza su producción a partir

2 Publicada por el Centro Editor de América Latina en 1983, esa "Historia" escrita por Arévalo se presenta como una continuación del Esbozo de Historia del Partido Comunista de la Argentina, de 1947. Como esta última, la de Arévalo es una "historia oficial" que está orientada por el mismo afán "propagandístico" y "autolegitimante" (Petra 52). 
de esos años se enlaza con una finalidad político-pedagógica que convierte a la literatura en una herramienta eficaz para lograr cambios en la vida de los hombres. Esa poética que González Tuñón comienza a explorar en su literatura de los 30 busca movilizar al público lector hacia la acción, de manera que es posible definirla como una poética de la convocatoria cuyo objetivo principal es exhortar, impulsar, convocar al lector, en otras palabras, sumar su voluntad a las causas defendidas por el partido. En los años 50, esa poética se elaborará, básicamente, a partir de dos operaciones fundamentales: en primer lugar, la exaltación de la lucha soviética y de otros movimientos independentistas por la defensa de la paz y la libertad en contra de esos intereses "foráneos" y, por otro, la denuncia de la violencia a la que son sometidos los pueblos de todo el mundo por el avance imperialista del país del norte. Asimismo esa convocatoria se asentará, en consonancia con el análisis de situación presentado por Arévalo, sobre una visión optimista del futuro según la cual la violencia ejercida por el imperialismo "yanqui" no es más que un signo indicativo de su inminente destrucción final. Así lo expresa en el poema "Catavi" de Hay alguien que está esperando: "Si agonía es lucha, los pistoleros yanquis luchan porque agonizan. / Tienen los días contados, o los años contados. / Pero yo sé que el tiempo los verá destruyéndose, sobre montañas de cenizas y huesos, sobre siglos de luto, sobre mares de llanto" (86).

\section{Del Congreso Continental de la Cultura al viaje por la Unión Soviética: las tareas de los intelectuales}

Entre el 26 de abril y el 3 de mayo de 1953, se lleva a cabo en Santiago de Chile el Congreso Continental de la Cultura, entre cuyos organizadores se contaba Pablo Neruda, quien acababa de regresar de la Unión Soviética, donde había participado como jurado del Premio Internacional por la Paz; un premio que, como su mismo nombre lo indica, se enmarcaba en la consigna de la lucha por la paz que sostuvo las estrategias políticas y culturales del Partido Comunista por esos años de la Guerra Fría. Junto a otros intelectuales del PCA como Héctor Agosti y Julio Galer, González Tuñón participa de ese Congreso con un discurso titulado "La batalla del espíritu". Como veremos, tanto los objetivos pautados por el Congreso como el discurso leído allí por González Tuñón requieren ser situados en el contexto de la preocupación comunista ante el imperialismo, y más concretamente, como respuestas a los programas de acción partidarios or- 
ganizados en torno a las consignas de la "defensa" de las culturas nacionales contra el "cosmopolitismo" norteamericano y la lucha por la paz.

En efecto, según las resoluciones del Congreso que reproduce el número 12 de Cuadernos de Cultura, el principal órgano de difusión cultural del PC local, los temas pautados sobre los cuales debían deliberar los intelectuales allí reunidos eran el "estímulo al libre desarrollo cultural de los pueblos americanos", el "incremento del intercambio cultural entre los países del continente y extracontinentales" y, por último, la "defensa de la ética profesional, la libertad de creación y de opinión" (7). La nota editorial que abre ese número de la revista, señala, además, que el temario, cuyo eje problemático era la "preservación de una cultura libre", se definía en relación a la gran amenaza que entrañaba para las culturas nacionales el avance del imperialismo; amenaza que requería la formulación de un programa de acción cuya finalidad principal estuviera asociada a la defensa de la independencia nacional de todos los países del continente y, concomitante con ella, a la defensa de la paz:

Intelectuales provenientes de todos los horizontes ideológicos coincidieron en que hay una amenaza de origen imperialista que pesa oprobiosamente, con los signos de la decadencia cosmopolita, sobre dichas culturas nacionales, y también en que la preservación de una cultura libre es inseparable de la efectiva independencia nacional de todos los países de América, afirmada en lo exterior por una política de paz y en lo interior por la plena vigencia de los derechos ciudadanos. (1-2)

Ahora bien, según se aclara en esa misma nota editorial de Cuadernos, la delimitación de este nuevo enemigo requería establecer una división clara entre la "camarilla plutocrática" y el "pueblo norteamericano" que, al igual que los pueblos del centro y del sur del continente, padecían las consecuencias de las políticas de represión y sometimiento llevadas adelante por los poderes imperialistas:

$[\ldots]$ no somos enemigos de los Estados Unidos, como quiere hacerlo creer la prensa subvencionada por el State Department; no somos enemigos de su pueblo, ni de sus tradiciones democráticas; somos, por el contrario, solidarios con ese mismo pueblo, igualmente sometido, igualmente extorsionado por las clases dominantes de su país; somos amigos del pueblo de los Estados Unidos, pero adversarios irreconciliables de la camarilla plutocrática que quiere convertirnos, cada vez más, en cipayos sumisos para sus planes de dominación imperialista del mundo. (4) 
Acorde con los diagnósticos, los objetivos y las tareas intelectuales fijados por el Congreso, en "La batalla del espíritu", González Tuñón llama a los intelectuales a unirse en "defensa de la cultura y de la paz" (18), en un momento en que "la poderosa realidad de los hechos humanos fundamentales [...] estremece los precarios cimientos de la torre de marfil" (16). De acuerdo a González Tuñón, como en el pasado lo fuera la amenaza fascista, en la actualidad, es el problema en torno al enemigo imperialista -que en su poesía será caracterizado precisamente como el "nuevo nazi" (Hay alguien que está esperando 116) o el "depositario de la herencia nazi" (106) - el que funda un deber para los intelectuales, en tanto "hoy, como ayer, están otra vez en juego los derechos humanos" (Cuadernos de Cultura 15). Para González Tuñón, entonces, la lucha antiimperialista reedita los imperativos de acción de aquella otra que, décadas atrás, los intelectuales entablaron contra el fascismo. En este sentido, si, como sostiene Petra, "la idea de que los Estados Unidos representaban un nuevo tipo de fascismo" les permitió a los intelectuales del PG "operar sobre una sensibilidad preexistente" (189), no es casual que la estrategia de apelación a la unión utilizada por González Tuñón se oriente precisamente a trazar una línea de continuidad entre la lucha antifascista de ayer y la lucha antiimperialista de hoy. Así, si el fascismo puso en juego los derechos más inalienables del hombre, González Tuñón enumera una serie de acontecimientos actuales protagonizados por el enemigo norteamericano -tanto en políticas externas como internas- que demuestran que estos se encuentran nuevamente en peligro y, por ende, funcionan como un argumento contundente para convocar a la unión de los intelectuales en un frente común de acción, en otras palabras, fundan un deber. Dice el autor:

Están en juego en Corea, donde los invasores yanquis enardecidos por resonantes fracasos apelan a la guerra bacteriológica. Están en juego en los mismos Estados Unidos, donde matan un ciudadano negro cada doce horas y han sido condenados a morir en la silla eléctrica dos intelectuales valientes y dignos: los esposos Rosenberg. Están en juego en Sudáfrica, por la misma atroz discriminación racial. Están en juego en Vietnam. Están en juego allí donde oscuras fuerzas foráneas medran, esclavizan e intrigan. Están en juego en España de las prisiones y el garrote vil. Están en juego en nuestros países latinoamericanos dependientes y semicoloniales y en cuya mayoría no existe la libertad de pensamiento o se obstaculizan las actividades del espíritu. Por eso afirmamos que no hay divorcio entre los problemas de la cultura y los problemas del hombre y 
asimismo están en juego los derechos de los pueblos a desarrollarse y, a ser libres y vivir en paz. $\left(15^{-16)}\right.$

Ahora bien, esa convocatoria a la unión intelectual, que se sostiene en un diagnóstico de situación caracterizado por la amenaza imperialista sobre la humanidad, redundará también en la formulación de un programa literario -más ampliamente, artístico- capaz de intervenir en la lucha antiimperialista en favor de la paz y la libertad de los pueblos; o, para decirlo con las palabras de González Tuñón, capaz de convertir la palabra en un "arma" (16). Ese programa supone una práctica literaria que sea "libre" y "moderna" "por su forma" y "principalmente social, realista, en su contenido" (17) y, más adelante en el texto, se revela como "el camino del realismo socialista" (18), entendido como "una guía" que no limita la creatividad del escritor sino que, por el contrario, la potencia y la estimula. Sin embargo, si el realismo socialista es la expresión de un mundo reconciliado donde ya no existe la lucha de clases, la literatura latinoamericana, por su parte, debe "saber adaptar" (18) la doctrina soviética a una realidad diferente, "no socialista", es decir, signada por el imperialismo y la lucha de clases.

Apenas unos meses después del Congreso Continental de la Cultura -y de la muerte de Stalin-, González Tuñón emprende su primer viaje por la Unión Soviética y China, como miembro de la delegación cultural de argentinos, invitados por el Instituto de Relaciones Culturales de la URSS. ${ }^{4} \mathrm{Al}$ regreso de ese viaje, publica Todos los hombres del mundo son

3 Ahora bien, esta modernidad formal se encuentra muy lejos de ser una reivindicación de la vanguardia. De hecho, si bien González Tuñón reconoce la importancia de la vanguardia "como reacción saludable contra el academicismo, la crítica oficial, la estética congelada, el sonsonete, lo reaccionario formal, la incomprensión burguesa" (17); señala que su pervivencia en la actualidad es signo de una actitud formalista o, peor aún, encubre un contenido reaccionario. En cambio, su superación por parte de "los escritores progresistas", les ha permitido encaminarse hacia un "arte clásico" capaz de "perdurar". Desde una mirada dialéctica del arte, esta superación es una suerte de síntesis que recupera la "herencia progresista" y se encuentra en la línea del "nuevo realismo".

4 De la delegación formaban parte los médicos Calzaretto, Reggiani, Vera y Thenon; el odontólogo Halpern; el escultor Falcini; el abogado Armengol; la pedadoga Perelstein; el escribano Viale; el actor Ricardo Passano y los escritores, periodistas e intelectuales Héctor Agosti, Guidiño Kramer,Juan Calvo y González Tuñón. Además de ese diario testimonial, que incluye poemas, discursos grabados para Radio Moscú y algunos ensayos, González Tuñón escribe un artículo (donde repite básicamente las mismas ideas que en Todos los hombres) 
hermanos, un extenso diario cuyo propósito es oponer un relato de la paz, la alegría y la libertad del pueblo soviético frente a la "política de mutua intransigencia e incluso de rivalidad permanente" que, tal como afirma Hobsbawm, marcó el escenario de la polarización de la Guerra Fría. Así, a los discursos del bando estadounidense que presentaban "el escenario de pesadilla de una superpotencia moscovita lanzada a la inmediata conquista del planeta, al frente de una conspiración comunista mundial y atea siempre dispuesta a derrocar los dominios de la libertad" (235), González Tuñón contrapone la descripción de un mundo que ha ejecutado una utopía colectiva: la de hacer posible la paz, la libertad y la igualdad en todos los órdenes de la vida. En este sentido, la búsqueda que orienta Todos los hombres es documentar lo que tuvo oportunidad de ver durante su viaje para refutar con su testimonio a los detractores del régimen soviético y revelar, además, un patrón a seguir para los países aún sometidos al capitalismo. ${ }^{5}$ De lo que se trata, específicamente, es de mostrar las bondades que ofrece el socialismo sobre el capitalismo con el fin último de persuadir al lector acerca de la necesidad de defender a la Unión Soviética en su lucha contra el imperialismo. De este modo, en Todos los hombres, la valoración de la vida en las sociedades socialistas se va tramando, fundamentalmente, por oposición a la de las sociedades capitalistas, que constituyen el polo negativo del paradigma comparativo que organiza González Tuñón:

Aquí, al penetrar poco a poco en la vida soviética, en su prodigio ejemplar, frente a un mundo capitalista decadente y devorado por los imperialismos, la realidad se conforma, como era lógico, a la idea que fue la fuerza motora que me hizo soñar alguna vez. [...] Porque aquí no existen las diferencias de clase

para el libro Al encuentro de dos culturas que el Instituto de Relaciones Culturales Argentina - URSS publica también en 1954. De ese libro participan todos los miembros de la delegación argentina dando a conocer sus impresiones de la URSS en lo que respecta al ámbito específico de sus especialidades.

5 No es casual, en este sentido, que el autor presente a China, un país agrario y, hasta hace poco, dominado por el imperialismo, como un modelo para Latinoamérica. Dice González Tuñón, en este sentido, que la experiencia de esa "nueva China" "interesa vivamente a los latinoamericanos, pues era un país agrícola en un ochenta por ciento y los imperialistas lo acosaban. Con razón, no hace mucho, el eminente Kou Mo Jo, poeta, dramaturgo, investigador, traductor, uno de los vicepresidentes de China, pudo decir, tan breve y elocuentemente, durante el homenaje a la memoria de José Martí: 'El pasado de China es el presente de América Latina y el presente de China es el futuro de América Latina" (Todos los hombres del mundo son hermanos 161). 
ni la explotación del hombre por el hombre; porque aquí el arte y la cultura están al alcance de todos (libertad de expresión, libertad de crítica, no son el privilegio de una minoría reaccionaria [...]. (33)

Siguiendo el itinerario trazado por estas observaciones iniciales, lo que relata González Tuñón en ese diario y en los poemas que allí incorpora es la experiencia de encontrarse ante una sociedad ideal que ha superado todas las barreras divisorias del mundo capitalista: una sociedad que no olvida el dolor causado por el nazismo durante la guerra, pero que, gracias al comunismo, se encuentra en rápido proceso de modernización y reconstrucción. Al mismo tiempo, es precisamente la experiencia de haber atravesado el dolor de la guerra contra la "barbarie" nazi la que, desde la óptica del autor, hace de estos países los principales defensores de la paz y la libertad contra las fuerzas imperialistas, que, por el contrario, quieren llevar al mundo por el camino de una tercera guerra:

He conocido de cerca, pues, lugares donde se desarrolló gran parte del drama de la última guerra mundial. He visto cómo gracias al socialismo y la democracia popular esos países que la guerra azotó bárbaramente [...] se recuperaron rápidamente y reconstruyeron lo que fue destruido. ¡Pero los muertos no pueden se reconstruidos! Y por lo tanto, esos pueblos que hoy cumplen un destino victorioso, no han olvidado la tragedia y son los más fervorosos defensores de la paz en el mundo y la defenderán con toda su alma y con todas sus armas, contra los criminales traficantes que quieren una tercera guerra mundial. (11-12)

Retomando las ideas desarrolladas en "La batalla del espíritu", en Todos los hombres, la comparación del modo de vida en los países socialistas con el de los países que enfrentan la amenaza imperialista se presenta como una suerte de sustento para comenzar a pensar un programa para el arte de los países latinoamericanos. Ese programa, como en "La batalla", requiere la recuperación de los principios educativos, estéticos y morales del arte soviético, aunque ahora en función del "reflejo" de una realidad diametralmente opuesta. De este modo, dado que los países "nosocialistas" se encuentran aún en "etapa de lucha" deben llevar adelante, dice González Tuñón, un "arte de agitación" capaz de "reflejar", "combatir", "exaltar" e "interpretar" una realidad signada por "las diferencias de clase". En esta dirección, el arte latinoamericano, en las antípodas del de los países socialistas donde las masas "han sido elevadas al nivel del arte", 
debe responder, de acuerdo a González Tuñón, a ese principio sostenido por Lenin según el cual: "El arte pertenece al pueblo [...] debe ser comprensible para estas masas y amado por ellas. Debe unificar el sentimiento, la idea y la voluntad de estas masas y elevarlas" (168; cursivas en el original). La tarea de los escritores latinoamericanos consistirá, entonces, en adecuar las pautas del realismo socialista a la realidad histórica y social de cada país para cumplir con la misión de movilizar al público a la lucha contra la dominación impuesta por el capitalismo. Se trata, en definitiva, no de exhibir -"reflejar" o "interpretar", en palabras de González Tuñónlas bondades del mundo comunista, como le corresponde al arte soviético, sino de confrontar a los lectores con su propia realidad para "elevarlos" y "unificar su voluntad", es decir, crear conciencia para incentivarlos a la acción transformadora.

Al mismo tiempo, acorde con ese programa antiimperialista fijado por el PC, la propuesta artística diseñada por González Tuñón está pensada en contrapunto con la novela y el cine hollywoodense, en sus vertientes "rosa" y "negra", que, una por su "morbosidad" y la otra por su "trivialidad" se alejan de ese programa de un arte útil a los procesos revolucionarios -es decir, de un arte educativo y formador- y, en cambio, reproducen la "moral imperialista" que se niega a buscar las causas de los males sociales. González Tuñón critica este tipo de arte a partir del ejemplo de la película Carretera 301, un filme estadounidense de 1950, dirigido por Andrew Stone, que cuenta la historia de una banda de ladrones y asesinos en su carrera de delincuencia feroz:

Según su relato y la declaración de un personaje al final, "los criminales son natos y hay que liquidarlos". ¡ No hay ninguna chance! No hay salida en el mundo del capitalismo, del imperialismo... Hay que matar a los delincuentes sin antes preguntarse por qué delinquieron, qué causas crearon el delito. Hay que encerrar al loco y darle de palos... Debe ser nato, también. Pero hay que dejar en libertad a los que hacen trabajar a los niños, a los que torturan en los reformatorios, a los gangsters de la alta Banca, a los vendedores de armamentos y acentuar las condiciones sociales de los que producen enfermos, locos, delincuentes. Esta es la moral del imperialismo. (40)

Se trata, en fin, de un arte que no ofrece salida puesto que, al servir a los intereses de la clase burguesa y del imperialismo, su propósito es proyectar un mundo inmutable, evitando así cuestionarse o profundizar 
en las causas de los "males sociales" para reproducir ese estado de injusticia y acentuar, así, la distancia entre explotados y explotadores. Según el autor, entonces, ese arte imperialista, lejos de esclarecer la conciencia del explotado acerca de su condición, pretende, por un lado, mantenerlo en su ignorancia y, por otro, seguir justificando la explotación de los poderosos sobre ellos.

Concordante con la propuesta literaria que formula en "La batalla del espíritu" y profundiza en Todos los hombres, a partir de Hay alguien que está esperando (el penúltimo viaje de fuancito Caminador), publicado un año antes, en 1952, y hasta el último poemario publicado en vida por el autor - La veleta y la antena, de 1969- el problema en torno al imperialismo se constituye, en efecto, como el eje central en torno al cual el autor construye su poética de la convocatoria. Como veremos, esa literatura se urde, precisamente, con los materiales que proveen todos los acontecimientos que, según señalaba en "La batalla", ponen en riesgo los derechos del hombre. La Guerra de Corea, los conflictos en los países coloniales, la violencia contra los negros y los comunistas en Estados Unidos, entre muchos otros, serán los anclajes a partir de los cuales González Tuñón intenta llevar a la práctica ese programa de un arte de "agitación" capaz de convocar al lector a la defensa de las culturas nacionales y de la paz contra las fuerzas imperialistas que amenazan con destruirlas.

\section{La poesía contra el imperialismo}

La convocatoria a la lucha contra el imperialismo en la literatura de González Tuñón se despliega a partir de un registro eminentemente argumentativo que apela a dos operaciones complementarias. Por un lado, del mismo modo que en Todos los hombres, a la construcción de una imagen de la Unión Soviética como defensora de la paz y la libertad en el mundo. Por otro, y como contracara de esa primera operación, la convocatoria se procesa a partir de un afán denunciante de la agresión imperialista. En todos los casos, como veremos, las modulaciones de la propaganda y la denuncia en los poemas del autor se van tramando a partir del procesamiento de los materiales que ofrecen los acontecimientos de la más candente actualidad, cuya evaluación siempre concuerda con la óptica de los análisis partidarios.

La misma idea acerca de la Unión Soviética como baluarte de la lucha por la defensa de la paz y la libertad contra el imperialismo que se ponía en juego en Todos los hombres aparece, por ejemplo, en "Claro clamor" de 
Hay alguien que está esperando, un largo poema dividido en cuatro partes, tituladas "No sólo trajo sangre y luto", "La paz es una e indivisible", "El poeta envía algunos mensajes" y "Paz Amor". Nuevamente, el rol asumido por la Unión Soviética en la Segunda Guerra se constituye como el anclaje indispensable para pensar su lugar en la lucha actual contra el nuevo enemigo. El poema busca, polémicamente, tal como se declara en el epígrafe de la primera parte, refutar "la teoría según la cual la última Gran Guerra no habría traído ni libertad, ni justicia" (112). Y, en esta dirección, habilita otra mirada sobre los resultados de la guerra: "No sólo trajo sangre y luto y nada. / Dos infamias cayeron bajo su justo plomo: / el nazismo, el fascismo, la sombra de la sombra. / Y las nuevas repúblicas libres y populares nacieron de sus ruinas" (112). A lo largo del poema, que está atravesado por una clara finalidad argumentativa, no sólo se revaloriza el rol de la Unión Soviética -metaforizada como el "Jefe de la paz" (115)- en la lucha contra el fascismo en la Segunda Guerra sino que, además, ese rol se evalúa positivamente en su proyección en la actualidad. Así, de acuerdo a la imagen que se desprende del poema, la Unión Soviética aparece como el principal defensor de la paz contra las "fuerzas regresivas" que "subsisten", dice González Tũ̃ón desde el epígrafe de la segunda parte, "en los grupos imperialistas, principalmente yanquis, a quienes sus propios pueblos rechazan, junto a los demás hermanos de la tierra, decididos a impedir una nueva guerra sin sentido" (114). De este modo, "Claro clamor" elabora una suerte de relato de la historia reciente y un análisis de la actualidad que funda un imperativo sustentado, como respuesta a los programas del PC, en el llamado a la defensa de la paz: "Cuando primaverales -corrían allá los días de un tibio mes de mayo- / entraron en Berlín las avanzadas del Ejército Rojo, / advino memorable la paz que hoy defendemos, / esa que conquistaron y a la que afirmaremos" (113).

Ahora bien, como señalé más arriba, la operación poética complementaria a esa exaltación de la Unión Soviética es la denuncia de los crímenes cometidos por el imperialismo. Pero, a su vez, esta intención denunciante se orienta en dos direcciones diferentes: en primer lugar, hacia el exterior, es decir, hacia el develamiento de la violenta intromisión de esos intereses imperialistas en los pueblos de los países coloniales o "semicoloniales" de todo el mundo; y, en un segundo movimiento, hacia el interior del mismo espacio enemigo, buscando exponer ante el público lector la crueldad de las políticas represivas ejercidas por el imperialismo hacia el propio pueblo norteamericano. La primera dirección se hace explícita, por ejemplo, 
en poemas como "Catavi", "Coral Corea (1)" y "Coral Corea (2)" de Hay alguien que está esperando o "El hongo y la rosa", "Mientras él agoniza" y "La sombra sobre el mapa" de La veleta y la antena. En todos ellos, el disparador de la escritura poética es algún acontecimiento político, bélico o social de actualidad que, evaluado desde la perspectiva que ofrecen los programas y diagnósticos partidarios, viene a constituirse como expresión acabada del avance del imperialismo contra la libertad y la paz de los pueblos del mundo. Así, "Catavi" tiene como núcleo temático la masacre ocurrida en diciembre de 1942, en las minas de Catavi, Bolivia; ${ }^{6}$ por su parte, como su mismo nombre anuncia, los dos poemas titulados "Coral Corea" funcionan como una intervención contra la violencia ejercida por los Estados Unidos en la Guerra de Corea; "Mientras él agoniza" está dedicado, según declara el autor desde el epígrafe, a la huelga de hambre iniciada por el líder independentista puertorriqueño Pedro Albizu Campos en la cárcel; "La sombra sobre el mapa" también lleva un epígrafe que contextualiza al poema, esta vez, en el marco de la connivencia entre el imperialismo norteamericano y el gobierno franquista ${ }^{8} \mathrm{y}$, por último, "El hongo y la rosa" complejiza la dinámica referencial en tanto se trata de un poema que glosa una pintura de Raúl Schurjin inspirada en la masacre provocada por la caída de la bomba atómica sobre Hiroshima y Nagasaki al finalizar la Segunda Guerra. En este último, es una obra artística, que expone la violencia mortífera de las fuerzas imperialistas, la que potencia la capacidad denunciante del poema, de manera que el mecanismo que pone en funcionamiento consiste en otorgar palabras a la violencia expuesta pictóricamente, en un intento por señalar al lector

6 Durante los sucesos de Catavi, los trabajadores que se encontraban en huelga, reclamando por mejoras en las condiciones laborales y aumento de los salarios, fueron ametrallados por las fuerzas militares.

7 La guerra se inicia en junio de 1950 cuando Corea del Norte, que había establecido un gobierno comunista, invade Corea del Sur. Como señala Hobsbawm, de esa guerra participó oficialmente Estados Unidos pero no la Unión Soviética, cuya colaboración con las fuerzas del Norte se mantuvo en secreto y camuflada bajo la ayuda de China. En cambio, los Estados Unidos, "bajo el disfraz de las Naciones Unidas", intervinieron Corea en 1950 con el objetivo de "impedir que el régimen comunista del norte del país dividido se extendiera hacia el sur" (241).

8 Dice el epígrafe: "A propósito de las bases yanquis en Albacete, Ávila, Barcelona, Bilbao, Cádiz, Coruña, Islas Baleares, Islas Canarias, León, Lugo, Madrid, Murcia y Sevilla, entregadas por Franco y la Falanje" (La veleta y la antena 109). 
la necesidad de elaborar en torno a esas imágenes una memoria colectiva de la guerra: "Que aquello que denuncia esta tela transida / sacuda las conciencias dormidas, y al olvido / demande, y que conmueva a los que no vivieron / tanta muerte en el mundo" (González Tuñón, La veleta y la antena 49). Si, como señala Susan Sontag, "la memoria colectiva no es un recuerdo sino una declaración: que esto es importante y que ésta es la historia de lo ocurrido [...] Las ideologías crean archivos probatorios de imágenes, imágenes representativas, las cuales compendian ideas comunes de significación [...]" (100; cursivas en el original), podría decirse que "El hongo y la rosa" enuncia un principio poético que se extiende a toda la producción literaria antiimperialista del autor: la poesía deviene, de este modo, un archivo de la violencia de la historia, reconstruye los acontecimientos para fundar allí la necesidad de la memoria y, con ella, un imperativo de acción.

Al mismo tiempo, ese relato se concentrará, con insistencia, en la delimitación acusatoria del enemigo imperialista. En esta dirección, los poemas recurren a un procedimiento de caracterización del otro antagónico que consiste en la extensa enumeración descriptiva, a partir de frases adjetivas o verbales, que operan al modo de una acumulación de epítetos o aposiciones, destacando sus cualidades monstruosas: "los nuevos nazis de antiguo cuño bucanero, / esa peste que ofende la Oración del Pionero / y agrega a las estrellas de la bandera que Lincoln amaba, / una estrella de sangre y una estrella de barro", dice en "Catavi" (González Tuñón, Hay alguien que está esperando 85). Ese procedimiento de expansión acumulativa adquiere aún mayor intensidad en "Coral Corea (1)", donde la serie de epítetos infamantes recurre a registros diferentes que van desde referencias literarias - como la novela Babbitt de Sinclair Lewis- hasta datos históricos o de la más candente actualidad: ${ }^{9}$

Usurpadores de California, Texas, Florida y Puerto Rico. / Asaltantes de Cuba y Filipinas. / Piratas del Caribe. / Linchadores de negros. / Masticadores de goma. / Enemigos del vino y la cigarra. / Convencionales del frejol en lata. / Depositarios de la herencia nazi; comadres de las lágrimas tardías. / Detractores de Lincoln y de Whitman, de Roosevelt

9 La novela de Lewis, publicada en 1922, constituye una crítica, en clave de sátira, a la clase media estadounidense. La referencia a Babbitt aparece con cierta recurrencia en los poemas de González Tuñón de este periodo, para reforzar la crítica a la hipocresía de la sociedad estadounidense y del "sueño americano". 
y de Chaplin. / Peste de Hearst, / Estolidez de Babbitt. / Celestinas del dólar. / Cloaca del Reader Digest. / Rotarios de la infamia. (106)

Ese gran enemigo focalizado de manera puntual en Estados Unidos, que siempre aparece señalado como "foráneo", "extranjero", "ajeno" a los intereses propios de los pueblos, tiene también su versión interna en "la antipatria unida a la máquina odiosa", que, en la cadena de valoraciones partidarias que organiza la poesía de González Tuñón, es enjuiciado como "más terrible" (86) incluso que el imperialismo norteamericano. En "La sombra sobre el mapa", por su parte, ese enemigo interno vuelve a adoptar la forma fascista de manera que la denuncia requiere, nuevamente, volver la mirada sobre el pasado, como prisma que permitirá analizar el presente: "Franco y Falanje y toda la campaña / primero abrió las puertas a los moros / y ahora el Pentágono quiero atar a España. // Primero abrió sus puertas a los moros / y a las manadas nazis y fascistas [...] Y hoy con el puñal imperialista / hiere a la Madre en todos sus costados" (González Tuñón, La veleta y la antena 111-112).

La intervención poético-política contra el avance del imperialismo norteamericano tiene otro núcleo temático que, al igual que en el caso de las guerras y las luchas sociales, se conecta directamente con los acontecimientos de su actualidad: los avatares de la carrera espacial, como episodio singular de la rivalidad tecnológica entre las dos superpotencias enfrentadas en la Guerra Fría. De acuerdo a Oscar Terán, la puesta en órbita del primer satélite artificial soviético -el Sputnik, en octubre de 1957- ${ }^{10}$ significó para los comunistas una corroboración de la superioridad científica y tecnológica de la Unión Soviética sobre los Estados Unidos y "alentó", tanto dentro de los Estados Unidos como en el resto del mundo, "la creencia" en "la decadencia generalizada de la sociedad capitalista" (101). En esta dirección, poemas como "La alegre canción del camarada Sputnik", "Balada lunar para el Lunik", "Buenos días, Señora la Luna" y "Poema en la órbita del futuro" de Demanda contra el olvido funcionan como una manifestación de entusiasmo celebratorio ante los progresos espaciales soviéticos, que busca exponer ante el lector los beneficios que

1o Al lanzamiento del Sputnik le siguieron otros avances tecnológicos, entre ellos el programa Lunik, basado en un sistema de sondas automáticas dedicadas al estudio de la luna, que se inició en 1959. Pero, además, en 1961, la Unión Soviética se convirtió en el primer país en enviar a un hombre, Yuri Gagarin, al espacio. 
entraña para el mundo el poderío soviético sobre la amenaza norteamericana. Así, en esos poemas, los logros espaciales de la Unión Soviética son celebrados como un avance del "sueño" comunista que trae una esperanza de paz para el mundo: "gracias ahora a los que traspusieron / la barrera del sueño y de la soledad / y a los que a usted llegaron en forma de cohetes / y esperanza, / ayudará a la vida, acercará a los mundos / y será una ventana para mirar la tierra..." (González Tuñón, Demanda contra el olvido 6o). Pero, además, los avances soviéticos en la conquista del espacio se organizan en la poesía de González Tũón como una suerte de zona poética miscelánea que conjuga la exaltación de la Unión Soviética con la luna como tema de la tradición poética, o también el impacto del progreso tecnológico con el sueño, la magia y la aventura que envuelve la luna como símbolo literario: "'-Hace años usted fue comparada / con el pobre Pierrot, payaso triste, / enharinado y lánguido tocador de violín; / con el 'fondo abollado de una cacerola [...] los veneramos, les agradecemos / por haber descubierto el otro lado / que tiene la aventura" (6o-61).

Sin embargo, esta celebración poética encuentra su contracara en el poema "La aventura quebrada" de La veleta y la antena. Allí, el impacto de la llegada del hombre a la luna, que de algún modo viene a marcar el triunfo norteamericano en esa competencia por el dominio del espacio, se desvía hacia la denuncia contra el despliegue de la bandera norteamericana en la superficie lunar, como un "símbolo impuro que ha abolido / el decoro solemne de la Luna" (91). Si los logros tecnológicos espaciales de la Unión Soviética eran evaluados como una esperanza para el mundo, los norteamericanos, en cambio, son concebidos como un "desafío al honor y al futuro", es decir, como un peligro para la libertad y la paz. Por ende, el poema se concentra metonímicamente en una imagen puntual, la de la bandera norteamericana flameando en la luna, con el objetivo de reorientar la perspectiva desde donde debe ser evaluado el alunizaje:

Pero hay algo que ofende la hazaña y el desvelo / y quiebra la aventura de estos perplejos hombres [...] convirtiéndola en áspera, agresiva y violenta / como un desafío al honor y al futuro. / En la Luna, esta Calle de la Paz en el cosmos, / clavaron la bandera de las franjas intrusas / que onduló en las colinas del crimen en Vietnam / y es el paño pirata que ya había teñido / la sangre universal latinoamericana". (9o) 
Ahora bien, como señalé anteriormente, la denuncia contra el imperialismo norteamericano también toma otra dirección y se orienta hacia la exhibición poética de la violencia ejercida por ese enemigo en el interior de la sociedad norteamericana. La búsqueda de los poemas que toman esta segunda dirección será intervenir fundamentalmente en torno a dos problemas que se constituyen como una muestra acabada de los efectos del poder imperialista desde adentro: el de las políticas raciales, por un lado, y el de las políticas de censura y represión hacia el comunismo ejercidas por el macarthismo, por otro. Para rastrear el modo en que González Tuñón evalúa poéticamente las consecuencias de las políticas raciales y represivas norteamericanas, me detendré en "Esos cuatro negros linchados", un poema de Hay alguien y en "Un poema desde la cámara de la vida", "El crimen de Sing Sing" y toda la sección titulada "El país y el mundo. Pasaporte al futuro" de La veleta y la antena.

En el primero de esos poemas, "Los cuatro negros linchados", el autor recurre a un procedimiento de construcción muy singular que explota las potencialidades poéticas de esa "íntima estructura dual" que, de acuerdo a Giorgio Agamben, posee el testimonio (158): el de prestar la voz poética a los muertos, quienes podrán, así, en el interior del poema, denunciar en primera persona los crímenes cometidos contra ellos mismos. De este modo, el poema se construye como un relato en el que los muertos, asumiendo su propia voz, pueden denunciar a sus verdugos y, en ese movimiento, correr el velo de la impunidad y el olvido. ${ }^{11} \mathrm{Si}$, como señala Agamben, el "sujeto del testimonio está constitutivamente escindido" entre una impotencia y una potencia de decir y, en este sentido, "el testigo, el sujeto ético, es aquel sujeto que testimonia de una desubjetivización" (158), aquí, el poema despliega esa escisión por medio de un mecanismo que consiste en prestar la propia voz a aquellos que no pueden decir: quien puede hablar pierde, por momentos, esa capacidad para que aquel que no puede hacerlo, finalmente, tome la palabra. El poema se estructura, de este modo, en cinco partes que tienen diferentes sujetos de enunciación. Así, mientras que en cada una de las primeras cuatro "habla" cada uno de

11 Este procedimiento será retomado posteriormente, con un alcance aún mayor, en "Cantata para nuestros muertos", el poema que abre Demanda contra el olvido, donde González Tuñón da voz, como dice en el epígrafe a las "Víctimas de las policías 'bravas', la Sección Especial, los 'aliancistas' y otros mercenarios, a veces aleccionados por los agentes nazis y del F.B.I." (9). 
los cuatro negros asesinados por el poder norteamericano, en la última, por su parte, se separan dos voces que traban una suerte de diálogo inconcluso: la del nosotros que conforman los cuatro negros y la del poeta. En la dinámica de desdoblamiento de las voces enunciativas, entonces, el poema ilumina ese carácter complementario y, al mismo tiempo, no coincidente" que, siguiendo a Agamben, singulariza el vínculo entre el muerto, el verdadero testigo, y el testigo por delegación (158).

En las primeras cuatro partes, como acabo de señalar, cada uno de los muertos toma la palabra y da su explicación de las razones que lo llevaron a la muerte, razones que, en su índole arbitraria e injusta, condensan toda la fuerza de la denuncia contra la discriminación racial que impera en la sociedad norteamericana: "Subí a un tren para blancos" (Hay alguien que está esperando 102; cursiva en el original), dice el primero; "Le pisé un pie a una señora blanca. / Alguien me empujó, eso es todo" (102), explica el segundo; "Dicen que por violar a una muchacha blanca. / Lo confesó ella misma y por cincuenta dólares / -acaso hurtados a los fondos Marshall-" (103), señala el tercero, dejando deslizar también una segunda denuncia, de corrupción; "Robé un poco de leche para mi baby enferma" (104), expresa, por último, el cuarto negro.

Ahora bien, en la quinta parte del poema es una voz plural, la de los cuatro muertos, la que asume la instancia de enunciación, para anunciar un futuro compensatorio de reconciliación de las razas y fin de las injusticias: "Mientras morimos otros negros nacen y nacen otros blancos / y éstos sí que verán el alba sin siluetas de lívidos ahorcados, / sin sollozos de madres desgarradas y solas / y penetrantes ayes de nuestros chiquilines" (104). Los muertos se dirigen explícitamente a un interlocutor, el "poeta lejano", al que saludan antes de dar el "último suspiro", que, de acuerdo al desarrollo posterior del poema, parece ser el momento de pérdida definitiva de la facultad de hablar: "Adiós, poeta lejano que cantas por nosotros. / Recibe nuestro último suspiro" (104). Ese saludo, entonces, es la instancia que posibilita el pasaje hacia la palabra del poeta, pero el diálogo queda trunco en tanto los muertos ya no podrán responder. Asimismo, al tomar la palabra, el poeta -cuya voz aparece delimitada por un guion de diálogo y, en este sentido, permanece en cierto modo ajena dentro del poema- provee de un nombre a los cuatro muertos. Al otorgar nombres propios, el poema deviene, entonces, un espacio capaz de brindar un resguardo frente al olvido: "-Espera Jim, espera Tom, espera Charlie, espera Clarence... / Recuerdos para Lincoln" (104). En la poesía de González 
Tuñón nombrar es, entonces, una suerte de mecanismo capaz de rescatar a los muertos del anonimato al que estaban destinados para oponer a la política represiva impuesta sobre ellos, la posibilidad de construcción de una memoria colectiva.

En "Un poema en la cámara de la vida", "El crimen de Sing Sing" y en los cuatro poemas que conforman "El país y el mundo. Pasaporte al futuro", ${ }^{12}$ la denuncia contra la persecución al comunismo ejercida por el macartismo imperante en los años 50 se concentra en torno a dos casos concretos, de amplia resonancia internacional: los dos primeros poemas, en el caso de Ethel y Julius Rosenberg, un matrimonio de judíos norteamericanos que, en junio de 1953, fue condenado a la silla eléctrica bajo la acusación de trabajar para los servicios secretos de la Unión Soviética; y la sección "Pasaporte al futuro", por su parte, en el del abogado, actor, atleta y cantante negro, Paul Robeson, un importante activista de los derechos civiles de los negros en Estados Unidos. El modo en que los poemas construyen las figuras de Robeson y del matrimonio Rosenberg posibilita la delimitación de los campos antagónicos.

Concentremos un momento en "Pasaporte al futuro". Ya desde su título, el primer poema de la serie, "Comienzo del alegato", busca disponer al lector a efectuar una lectura jurídica del poema: revestido de la función de juez, el poeta toma a su cargo la defensa del "caso" para probar la inocencia del acusado y, por contraste, la culpabilidad del estado norteamericano. Ahora bien, ese registro jurídico se conjuga, por momentos, con un trabajo vanguardista de construcción a partir del montaje, que orienta la serie de "Pasaporte al futuro" en una dirección diferente, aunque complementaria. Así, otro de los poemas de esa sección, "En el país de hierro", trabaja a partir de la acumulación caótica de fragmentos de noticias, voces, discursos, personajes históricos e imágenes de violencia que se disponen azarosamente sin respetar ninguna pauta gramatical de puntuación, de manera tal que consiguen crear un efecto de desorden y confusión. Sin embargo, ese montaje, que en principio parece mera aglomeración sin coherencia, cumple, recuperando el concepto que Benjamin desarrolla en "El autor como productor" respecto del teatro épico de

12 Los poemas que integran esa sección de La veleta, dividen en partes y reescriben el largo poema "Pasaporte para un sueño" que González Tuñón había incluido en la última sección del segundo tomo de la antología La luna con gatillo, titulada "Selección de 'Florida antena' (de un libro inédito)". 
Bertolt Brecht, una "función organizadora" (8) puesto que no pretende "reproducir situaciones" sino "descubrirlas" (9), forzando al lector "a tomar postura ante el suceso". El eje que regula ese orden, obviamente, no es otro que el del fin del imperialismo; el poema va "descubriendo" un sentido para pensar el presente y el futuro del mundo:

(F.B.I. Prontuarios Embajadas espías Abogados de empresas tenebrosas Inversiones de capitales otro nombre que tiene la raza de los Armour los Purefoy los Beaulac y los Braden Uñas sangrientas valles de luto primaveras heridas huellas de los braseros fugitivos Miren algo que cae se viene abajo con barullo un sistema se desploma Tiemblan las ratas los sirvientes tiemblan Chiang Kai Shek Franco tiemblan títeres generales tiemblan Yo seré muchos dijo Espartaco Un esplandor [sic] lejano veo Otra época avanza y ninguna colonia quedará sobre el mapa flamante de la Tierra Algo marcha en el mundo Verdugos entreguistas demagogos algo marcha Es la delicadeza la paz el día final la poesía Es la nube es el suelo el horizonte el día nuevo el vino viejo y la esperanza). (González Tuñón, La veleta y la antena 121 ; cursiva en el original)

Ese desorden inicial, entonces, viene a constatar que "algo se cae se viene abajo con barullo algo se desploma" pero, al mismo tiempo, incluye una perspectiva de futuro, es decir, anuncia "el horizonte el día nuevo". Del caos al cosmos, como si se tratara de un nuevo Big Bang, la capacidad denunciante y la capacidad de dilucidación del futuro que posee la poesía según González Tuñón quedan conjugadas aquí a partir de múltiples registros que, como vemos, van desde el discurso jurídico al montaje vanguardista y el desbaratamiento de la gramática; registros que se complementan en el marco de una poética cuya función primordial es impactar en el lector con el fin de convocarlo a la lucha contra el imperialismo. Así, en "Un poema en la cámara de la vida", por ejemplo, la exposición del crimen cometido contra el matrimonio Rosenberg redunda en un explícito llamado a los "hermanos de los mapas americanos", sin distinción de razas o nacionalidades, a unirse en un "reclamo" colectivo contra el poder norteamericano, como peldaño necesario para lograr que un día sea el "odio" y no las personas que luchan contra él, el "ejecutado":

Blanco, negro, mulato, mestizo, hermanos / de los mapas americanos. / Del hemisferio como un ancho amor, / con sus alas de lluvia, su cordero y su puma / el destino esperando. / Golpee tu protesta las hostiles paredes / de la manchada Casa Blanca / donde un presidente dio la orden 
siniestra / mientras jugaba con sus nietos. / Reclamen por aquellos que en Sing Sing, en la cámara / de la muerte, aun cantan / porque saben que un día, al fin, el odio será el ejecutado / y un mundo que no olvida hacia otro mundo marcha. (105-106)

Tanto la celebración de la Unión Soviética como defensora de la paz y de la libertad en el mundo como la exposición poética de la denuncia contra el avance del imperialismo, tal como se despliegan en la poesía antiimperialista de González Tuñón, están orientadas por múltiples propósitos que, en última instancia, ponen en juego esa capacidad de acción que posee la literatura para intervenir en favor de la transformación de la realidad. En líneas generales, los poemas buscan confrontar al lector con la destrucción que produce la agresión imperialista sobre los pueblos -y, por contraste, con la lucha que la Unión Soviética lleva a cabo para promover la paz- para conducirlo, así, hacia una toma de posición ante la realidad que decante finalmente en acción. En esta dirección, la interpretación de los acontecimientos que exponen estos poemas va delimitando un interlocutor latinoamericano o, más puntualmente, argentino, al que se insta moralmente a participar de la defensa de la causa contra el avance de los norteamericanos en el mundo. En esta dirección, "Catavi", por ejemplo, define como destinatario a un lector argentino al que incita simbólicamente a apropiarse de los muertos bolivianos, que se convierten en una suerte de bandera de lucha: "Sombras de la Argentina, también son vuestros muertos" (86). Pero, además, la denuncia contra el imperialismo está asociada, en casi todos los casos, con una explícita exhortación a negar la ayuda y el apoyo a las fuerzas imperialistas, tal como se lee, por ejemplo, en los poemas titulados "Coral Corea": "Ni una gota de sangre, / ni una pizca de sal, / ni un gramo de carne, / ni un grano de cereal. // Atención, atención, América Latina. / Contra tambor de muerte / campana de vida" (107); "¡No más soldados, no más aporte a la UN / y los sirvientes del dólar y la horca! / ¡No más carne argentina para los nuevos nazis!" (111).

Para concluir, podría afirmar entonces que los poemas antiimperialistas de González Tuñón ensayan diferentes modos de poner en funcionamiento ese programa de adaptación del realismo socialista que, en "La batalla del espíritu" y en Todos los hombres del mundo, proponía como camino para el arte latinoamericano. Estos poemas, en última instancia, exploran las potencialidades de ese programa de un arte de "agitación" capaz de confrontar al lector con su propia realidad y movilizarlo a transformarla. 


\section{Obras citadas}

AA.VV. Al encuentro de dos culturas / Primera delegación cultural argentina en la URSS. Buenos Aires: Instituto de Relaciones Culturales Argentina-URSS, 1954. Impreso.

AA.VV. "El Congreso Continental de la Cultura". Cuadernos de Cultura 12 (Buenos Aires, julio de 1953): 1-6. Impreso.

AA.VV. "Resoluciones del Congreso Continental de la Cultura". Cuadernos de Cultura 12 (Buenos Aires, julio de 1953): 7-10. Impreso.

Agamben, Giorgio. Lo que queda de Auschwitz. El archivo y el testigo. HOMO SACER III. Valencia: Pre-Textos, 2009. Impreso.

Arévalo, Oscar. El Partido Comunista. Buenos Aires: Centro Editor de América Latina, 1983. Impreso.

Benjamin, Walter. "El autor como productor". Chile: CEME web productions, 2011. https://semioticaenlamla.files.wordpress.com/2011/o9/ el-autor-como-productor.pdf. Web. 19 de julio de 2015.

González Tuñón, Raúl. Demanda contra el olvido. Buenos Aires: Horizonte, 1963. Impreso.

González Tuñón, Raúl. Hay alguien que está esperando (El penúltimo viaje de fuancito Caminador). Buenos Aires: Carabelas, 1952. Impreso.

González Tuñón, Raúl. "La batalla del espíritu”. Cuadernos de Cultura $\mathrm{N}^{\circ} 12$ (Buenos Aires, julio de 1953), 15-18. Impreso.

González Tuñón, Raúl. La luna con gatillo. Buenos Aires: Cartago. Dos Tomos, 1957-1958. Impreso.

González Tuñón, Raúl. La veleta y la antena. Buenos Aires: Buenos Aires Leyendo, 1969. Impreso.

González Tuñón, Raúl. Todos los hombres del mundo son hermanos. Buenos Aires: Poemas, 1954. Impreso.

Hobsbawm, Eric. Historia del siglo XX. Buenos Aires: Crítica, 2010. Impreso. Petra, Adriana. Intelectuales comunistas en la Argentina (1945-1963) (Tesis de posgrado. Universidad Nacional de La Plata. Facultad de Humanidades y Ciencias de la Educación). Memoria Académica (2013). http://www.memoria. fahce.unlp.edu.ar/tesis/te.896/te.896.pdf. Web. 16 de marzo de 2016.

Sontag, Susan. Ante el dolor de los demás. Buenos Aires: Alfaguara, 2003. Impreso. 